\title{
Effects of brucine on bone metabolism in multiple myeloma
}

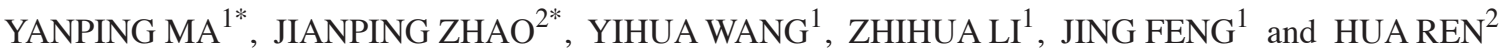 \\ ${ }^{1}$ Department of Hematology, The Second Hospital of Shanxi Medical University, Taiyuan, Shanxi 030001; \\ ${ }^{2}$ Shanxi College of Traditional Chinese Medicine and Western Medicine Hospital, Shanxi 030001, P.R. China
}

Received January 29, 2012; Accepted April 12, 2012

DOI: $10.3892 / \mathrm{mmr} .2012 .920$

\begin{abstract}
The aim of this study was to explore the effects of brucine on bone metabolism in multiple myeloma (MM) and to compare brucine and bortezomib regarding the effects on $\mathrm{MM}$ in vitro. The half maximal inhibitory concentration $\left(\mathrm{IC}_{50}\right)$ values of brucine and bortezomib in the MM cell line U266 were detected by MTT assay. In addition, the expression of alkaline phosphatase (ALP), osteocalcin (OC), osteoprotegerin (OPG) and osteoprotegerin ligand (also termed receptor activator of nuclear factor $\kappa \mathrm{B}$ ligand) (RANKL) at mRNA levels were measured by RT-PCR. $\mathrm{IC}_{50}$ of bortezomib in the $\mathrm{U} 266$ cell line at $48 \mathrm{~h}$ was $22.4 \mathrm{nmol} / \mathrm{l}$, and that of brucine was $0.16 \mathrm{nmol} / \mathrm{l}$. Compared with osteoblasts incubated with MM cell supernatant alone, the mRNA levels of ALP, OC and OPG in osteoblasts co-treated with brucine and MM cell supernatant were higher $(\mathrm{p}<0.05)$, while the mRNA expression of RANKL was lower, and the ranges of the changes were all larger than those of the group treated with bortezomib $(\mathrm{P}<0.05)$. Brucine exerts effects on bone metabolism in multiple myeloma through the regulation of osteoclasts by osteoblasts.
\end{abstract}

\section{Introduction}

Multiple myeloma (MM) is a common cancer, pathologically recognized by a continuous expansion of abnormal plasma cells in marrow, which leads to progressive damage of the bones, exerting profound influence on the life and prognosis of these patients. At present, most of the studies concerning the molecular mechanism of MM have focused on the activation mechanism of osteoclasts, however little is known about the inhibition mechanism of osteoblasts.

The chemotherapeutics currently available for MM include vincristine, dexamethasone (DXM), melphalan and various other medicines, but treatment with these agents may lead to the risk of other types of malignancies of the hemato-

Correspondence to: Professor Yanping Ma, Department of Hematology, The Second Hospital of Shanxi Medical University, No. 382 Wuyi Road, Taiyuan, Shanxi 030001, P.R. China

E-mail: mayanpingen@163.com

*Contributed equally

Key words: brucine, multiple myeloma, osteoblast, osteoclast logical system, such as myelodysplastic syndrome (MDS) (1). Proteasome inhibitors and bortezomib (Velcade ${ }^{\circledR}$ ), a newly developed medicine with potential effect on MM, have been recently introduced and are widely used in the treatment of recurrent and intractable MM (2). Their rates of efficacy, however, range between 40 and $60 \%$, even with acute side effects, dose-limiting toxicity and progressive drug fastness. It has been reported that preparations containing brucine are noticeably effective for abirritation, anti-inflammation, immunoregulation (3), osteoarthritis and inhibition of the apoptosis of cartilage cells $(4,5)$. Yet, the role of brucine in bone metabolism in multiple myeloma which is characterized by bone lesions requires exploration. Given the insufficient study on the function of osteoblasts in the mechanism of multiple myeloma, the present study aimed to explore the nosogenesis of MM from the perspective of both osteoblasts and osteoclasts.

\section{Materials and methods}

Cells. The MM cell line U266 was obtained from Bethune International Peace Hospital, Shijiazhuang, China. Mouse embryonic osteoblasts MC3T3-E1 were from the Cell Collection Center of Wuhan University, China (CCTCC code: CRL-2593).

Differentiation of osteoblast progenitor cells. Osteoblast progenitor cell line MC3T3-E1 was cultured in DMEM/high glucose medium containing $10 \% \mathrm{FBS}$ at $37^{\circ} \mathrm{C}$ in $5 \% \mathrm{CO}_{2}$. When the cells reached a fusion level of $90 \%$, they were subcultured in 6-well plates.

Fully-grown fusion cells were passaged at a ratio of 1:3, and $5 \times 10^{4}$ MC3T3-E1 cells were inoculated in 6-well plates. After $3 \mathrm{~h}$, when all the cells adhered to the side of the plate, the supernatant was collected, and the culture system mentioned above was implemented. Three days later the sugar medium was replaced and 6 days after the culture, cells were collected.

Differentiation of osteoblast progenitor cells. The MM cell line $\mathrm{U} 226$ was cultured at $37^{\circ} \mathrm{C}$ in $5 \% \mathrm{CO}_{2}$. Then $2 \times 10^{5} / \mathrm{ml}$ cells were inoculated in flasks of $75 \mathrm{~cm}^{2}$. Three days later, a sample of the suspended cells was centrifuged in 3 tubes (15 $\mathrm{ml}$ and $1000 \mathrm{rpm}$ ) for $5 \mathrm{~min}$. The centrifuged cells were then filtered using a sterile filter with an aperture of $0.22 \mu \mathrm{m}$ before they were preserved at $-70^{\circ} \mathrm{C}$.

The cultured osteoblast progenitor cells were divided into 2 groups: i) the blank control in DMEM/high glucose medium containing $10 \% \mathrm{FBS}$ and ii) the treatment group, containing 
Table I. Primer sequences.

\begin{tabular}{cc}
\hline Primers & Sequences \\
\hline ALP & \\
P1 & 5'-CCAGCAGGTTTCTCTCTTGG-3' \\
P2 & 5'-CCAGCAGGTTTCTCTCTTGG-3' \\
OC & \\
P1 & 5'-AAGCAGGAGGGCAATAAGGT-3' \\
P2 & 5'-TGCCAGAGTTTGGCTTTAGG-3' \\
OPG & \\
P1 & 5'-CTGCCTGGGAAGAAGATCAG-3' \\
P2 & 5'-TTGTGAAGCTGTGCAGGAAC-3' \\
RANKL & \\
P1 & 5'-AGCCGAGACTACGGCAAGTA-3' \\
P2 & 5'-GCGCTCGAAAGTACAGGAAC-3' \\
\hline
\end{tabular}

ALP, alkaline phosphatase; OC, osteocalcin; OPG, osteoprotegerin; RANKL, receptor activator of nuclear factor $\kappa \mathrm{B}$ ligand.

$30 \% \mathrm{MM}$ cell supernatant. A total amount of $5 \times 10^{4} \mathrm{MC} 3 \mathrm{~T} 3-\mathrm{E} 1$ cells were cultured on 6-well plates in complete medium containing $30 \%$ of MM cell supernatant. The medium was replaced 3 days later and the cells were collected 6 days later.

MTT analysis. The cell suspension was adjusted to $1 \times 10^{5} / \mathrm{ml}$ and the cells were transferred to a 96 -well culture plate, with each well containing $200 \mu \mathrm{l}$. To each experimental group, brucine of a different viscosity was added, but not in the control group. In addition to the above two groups, a blank control was also established (medium only but without cells). For each group, 3 parallel wells were available and the culture was carried out for $72 \mathrm{~h}$. A total amount of $20 \mu \mathrm{l}$ of MTT $(5 \mathrm{mg} / \mathrm{ml})$ was added to each well and $4 \mathrm{~h}$ later the cells were centrifuged and the supernatant was discarded. To each well, $150 \mu 1$ of DMEM was added, followed by a 10 -min oscillation before each group was tested for their absorbance value $\left(\mathrm{A}_{570}\right)$ using an automatic microplate reader. Finally, the cell growth inhibition rates were calculated. Cell growth inhibition rate $(\%)=\mathrm{A}_{\text {control group }}-\mathrm{A}_{\text {experimental group }} / \mathrm{A}_{\text {control group }}-\mathrm{A}_{\text {blank control }}$ $\mathrm{x} 100 \%$.

According to the linear regression equation, the half maximal inhibitory concentration $\left(\mathrm{IC}_{50}\right)$ of brucine was determined. The same process was followed using bortezomib.

Effects on MM bone metabolism. MC3T3-E1 cells were cultured on 6-well plates in complete medium contaning $30 \%$ MM cell supernatant. In the bortezomib-treated group, the $30 \%$ MM cell supernatant used was treated with bortezomib (at the concentration of $22.4 \mathrm{nmol} / \mathrm{l}$, which was the $\mathrm{IC}_{50}$ value of bortezomib) for $48 \mathrm{~h}$. In the brucine-treated group, the $30 \% \mathrm{MM}$ cell supernatant was treated with brucine (at the concentration of $0.16 \mathrm{mg} / \mathrm{ml}$, which was the $\mathrm{IC}_{50}$ value of brucine) for $48 \mathrm{~h}$.

$R T-P C R$. Total RNA was extracted from a total amount of $5-10 \times 10^{6}$ of marrow mononuclear cells using TRIzol one-step method (TRIzol is a new total RNA extraction reagent) and then were tested for their concentration and purity with a UV

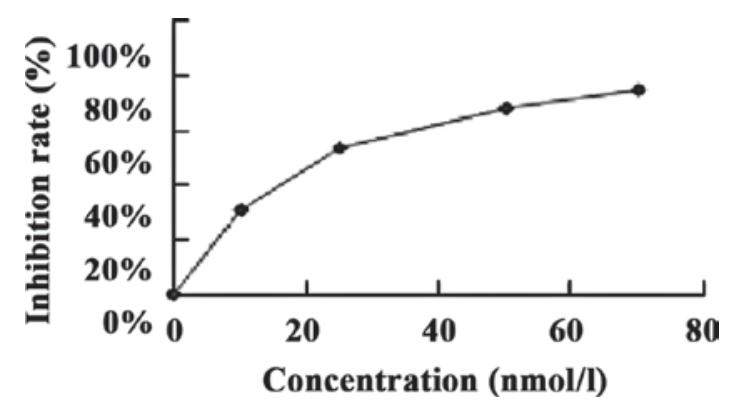

Figure 1. Inhibitory effects of bortezomib on U266 cells.

spectrophotometer. The primer sequences of alkaline phosphatase (ALP), osteocalcin (OC), osteoprotegerin (OPG) and receptor activator of nuclear factor $\kappa \mathrm{B}$ ligand (RANKL) are shown in Table I.

The 50- $\mu$ l PCR reaction system included a total amount of $2 \mu \mathrm{l}$ DNA, $1 \mu \mathrm{ldNTP}$ at $2.5 \mathrm{mmol} / 1,2.5 \mathrm{U}$ Taq Plus Polymerase, $5 \mu \mathrm{l} 10 \mathrm{X}$ buffer and $2.5 \mu \mathrm{l}$ primer $(10 \mu \mathrm{mol} / \mathrm{l})$.

The reaction conditions included an initial denaturation at $94^{\circ} \mathrm{C}$ for $5 \mathrm{~min}$, followed by 32 cycles of $94^{\circ} \mathrm{C}$ for $20 \mathrm{sec}$, $56^{\circ} \mathrm{C}$ for $20 \mathrm{sec}$ and $72^{\circ} \mathrm{C}$ for $20 \mathrm{sec}$. The PCR products were detected by agarose gel electrophoresis, followed by chart recording using ImageMaster UDS Gel analysis software. The process was repeated three times. The PCR amplification length was $239 \mathrm{bp}$ (ALP), 212 bp (OC), 226 bp (OPG) and 208 bp (RANKL).

Statistical analysis. SPSS 11.5 was adopted for the data analysis with all the results expressed as means \pm standard deviation (SD). ANOVA was chosen for pair-wise comparison.

\section{Results}

The results showed that the $\mathrm{IC}_{50}$ of brucine in the $\mathrm{U} 266$ cell line at $48 \mathrm{~h}$ was $47.84 \times 10^{4} \mathrm{nmol} / \mathrm{l}$, and that of bortezomib was $22.4 \mathrm{nmol} / \mathrm{l}$ (Fig. 1).

The ANOVA results between the target bands and the ratios to the GRAPH gene for the 4 groups were examined for OC, ALP, OPG and RANKL. The results showed that the P-values for the comparisons between the treated and the other 4 groups (control, supernatant (30\%)-, bortezomib- and brucine-treated) were $<0.05$, indicating a significant difference (Table II).

Brucine- and bortezomib-treated groups were significantly different in regards to levels of ALP, OC, OPG and RANKL $(\mathrm{P}<0.05)$, with the first three variables of the brucine-treated group larger than those of the bortezomib-treated group, while RANKL of the brucine-treated group was lower than that of the bortezomib-treated group, indicating that brucine is superior in its effects on MM.

\section{Discussion}

Extensive data indicate that the major effector cells that induce MM are osteoclasts (6), derived from mononuclear phagocyte system and are highly differentiated multiple-core cells capable of reabsorbing sclerotin (7). Osteoclasts in the marrow of MM patients, when stimulated by malignant plasma or other cells in the marrow microenvironment, increase in number and 
Table II. Differences in ALP, OC, OPG and RANKL of the 4 cell groups.

\begin{tabular}{lllll}
\hline Groups & \multicolumn{1}{c}{ ALP } & \multicolumn{1}{c}{ OC } & OPG & RANKL \\
\hline Blank control & $0.8166 \pm 0.0108$ & $0.9786 \pm 0.0034$ & $0.8646 \pm 0.0032$ & $0.2466 \pm 0.0054$ \\
Supernatant (30\%)-treated & $0.0956 \pm 0.0019^{\mathrm{a}}$ & $0.1888 \pm 0.0023^{\mathrm{a}}$ & $0.1557 \pm 0.0030^{\mathrm{a}}$ & $1.0820 \pm 0.0056^{\mathrm{a}}$ \\
Bortezomib-treated & $0.4830 \pm 0.0082^{\mathrm{a}, \mathrm{b}}$ & $0.6018 \pm 0.0008^{\mathrm{a}, \mathrm{b}}$ & $0.6211 \pm 0.0010^{\mathrm{a}, \mathrm{b}}$ & $0.7474 \pm 0.0014^{\mathrm{a}, \mathrm{b}}$ \\
Brucine-treated & $0.5277 \pm 0.0034^{\mathrm{a}, \mathrm{b}, \mathrm{c}}$ & $0.6833 \pm 0.0052^{\mathrm{a}, \mathrm{b}, \mathrm{c}}$ & $0.6782 \pm 0.0086^{\mathrm{a}, \mathrm{b}, \mathrm{c}}$ & $0.6890 \pm 0.0063^{\mathrm{a}, \mathrm{b}, \mathrm{c}}$
\end{tabular}

ALP, alkaline phosphatase; OC, osteocalcin; OPG, osteoprotegerin; RANKL, receptor activator of nuclear factor $\kappa \mathrm{B}$ ligand. All P-values are less than 0.05 , indicating that the overall differences in each variable across the four groups are statistically significant. ${ }^{a} \mathrm{P}<0.01$ compared with the blank control group; ${ }^{b} \mathrm{P}<0.01$ compared with the supernatant (30\%)-treated group; ${ }^{\mathrm{c}} \mathrm{P}<0.01$ compared with the bortezomib-treated group. Values are expressed as the means $\pm \mathrm{SD}$.

activity causing more active osteolysis (8). Additionally, where primary bone loss occurs, new born formation decreases or even disappears, causing an imbalance between osteolysis, which progresses rapidly, and subsequently osteogenesis decreases (or even disappears). These are exactly the major physiological features of MM. Studies of the mechanism of MM have focused mainly on the increase in osteoclasts both in amount and in activity while research on the role of osteoblasts in MM have received less attention. This study aimed to explore the nosogenesis of MM from two aspects: osteoclasts and osteoblasts (9).

The latest discovery that the OPG/RANKL/RANK system plays a vital role in osteoclastogenesis is a significant breakthrough in the field of bone physiology (10-12). The human body contains various cytokines and hormones which exert effects on bone metabolism by regulating the OPG/RANKL ratio in the microenvironment of marrow. Furthermore, the OPG/RANKL/RANK system was recognized only in recent years to be an important signaling pathway in the process of osteoclast differentiation $(13,14)$. In brief, RANKL, which is expressed on the surface of osteoblast/stromal cells, binds to RANK on osteoclast precursors or osteoclasts (15), and promotes osteoclastogenesis and bone resorption. However, OPG which is expressed by osteoblasts/stromal cells, strongly inhibits bone resorption by binding to its ligand RANKL and thereby blocks the interaction between RANKL and RANK. The main function of OPG is to inhibit the differentiation of osteoclasts and the resorption activity of mature osteoclasts and induce its apoptosis while its ligand, RANKL or OPGL, contributes to the differentiation of osteoclasts, vitalizes mature osteoclasts and prevents their apoptosis.

Therefore, the OPG/RANKL ratio serves as an important lever in keeping the balance between bone resorption and formation, and is also a significant indicator of bone remodeling. Furthermore, their balance determines the activity of osteoclasts and the resorption of mediated bone $(16,17)$. By secreting both OPG and RANKL, two key elements, osteoblasts regulate the activity of osteoclasts and play a critical role in MM (18).

The culture model of osteoblasts in vitro has shown that the differentiation of osteogenic progenitor cells (OPC) fall into three stages: cell proliferation, bone matrix maturation and bone matrix mineralization (19-21). In the second stage, i.e., bone matrix maturation, the ALP gene expression level reaches its peak and in the last stage, bone matrix mineralization, OC gene expression reaches a noticeable higher level (22).

The present study revealed that the mRNA expression of ALP, OC and OPG of an osteoblast cell line, after having been cultured in complete medium containing $30 \%$ multiple myeloma cell supernatant, decreased noticeably to much lower levels than those of the blank control group; however the mRNA of RANKL alone increased, which points to the conclusion that by breaking the balance between OPG and RANKL, multiple myeloma cells promote the differentiation of osteoclasts, vitalize their activity, prevent their apoptosis and inhibit bone generation. The brucine-treated group, however, showed quite different results. The mRNA expression of ALP, OC and OPG significantly increased while the mRNA of RANKL decreased, indicating that brucine inhibits the differentiation of osteoclasts, and promotes their apoptosis and bone generation. In addition, it shows that brucine is superior to bortezomib in regards to the therapeutic effect on MM.

In conclusion, this study explored the manner in which brucine affects osteoblasts and osteoclasts, (two key secretions of osteoblasts), in MM to regulate the differentiation and apoptosis of osteoclasts. Furthermore, it established a cell model in which MM cells inhibit early osteogenic differentiation paving the way for further study of the gene mechanism in which marrow tumors inhibit osteoblasts. At the same time, it revealed that brucine is superior to bortezomib in regards to the therapeutic effect on MM, which points out a new approach to the cure of MM.

In this research, RT-PCR was adopted to measure the amount of the elements at the gene level. In subsequent studies, real-time PCR detection methods may be an option for achieving better credibility and western blot analysis may be used to test protein levels.

\section{Acknowledgements}

This study was supported by the Scientific Research Projects of Shanxi Province Returned Students (2008, 10, 99).

\section{References}

1. Rao PS, Ramanadham M and Prasad MN: Anti-proliferative and cytotoxic effects of Strychnos nux-vomica root extract on human multiple myeloma cell line-RPMI 8226. Food Chem Toxicol 47: 283-288, 2008 
2. Spisek R, Charalambous A, Mazumder A, et al: Bortezomib enhances dendritic cell (DC)-mediated induction of immunity to human myeloma via exposure of cell surface heat shock protein 90 on dying tumor cells: therapeutic implications. Blood 109: 4839-4845, 2007.

3. Arron JR and Choi Y: Bone versus immune system. Nature 408: 535-536, 2000

4. Wang HW, Sharp TV, Koumi A, et al: Characterization of an anti-apoptotic glycoprotein encoded by Kaposi's sarcoma-associated herpesvirus which resembles a spliced variant of human survivin. EMBO J 21: 2602-2615, 2002.

5. Shen Y, Devgan G, Darnell JE Jr and Bromberg JF: Constitutively activated Stat3 protects fibroblasts from serum withdrawal and UV-induced apoptosis and antagonizes the proapoptotic effects of activated Stat1. Proc Natl Acad Sci USA 98: 1543-1548, 2001

6. Yuan LQ, Xie H, Luo XH, et al: Taurine transporter is expressed in osteoblasts. Amino Acids 31: 157-163, 2006.

7. Kanzaki H, Chiba M, Shimizu Y and Mitani H: Dual regulation of osteoclast differentiation by periodontal ligament cells through RANKL stimulation and OPG inhibition. J Dent Res 80: 887-891, 2001.

8. Boyle WJ, Simonet WS and Lacey DL: Osteoclast differentiation and activation. Nature 423: 337-342, 2003.

9. Khosla S: Minireview: the OPG/RANKL/RANK system. Endocrinology 142: 5050-5055, 2001.

10. Giuliani N, Colla S and Rizzoli V: New insight in the mechanism of osteoclast activation and formation in multiple myeloma: focus on the receptor activator of NF-kappaB ligand (RANKL). Exp Hematol 32: 685-691, 2004

11. Giuliani N, Colla S, Morandi F, Barille-Nion S and Rizzoli V: Lack of receptor activator of nuclear factor- $\kappa$ B ligand (RANKL) expression and functional production by human multiple myeloma cells. Haematologica 90: 275-278, 2005.

12. Heider U, Zavrski I, Jakob C, et al: Expression of receptor activator of NF- $\kappa$ B ligand (RANKL) mRNA in human multiple myeloma cells. J Cancer Res Clin Oncol 130: 469-474, 2004
13. Jakob F, Seefried L and Ebert R: Pathophysiology of bone metabolism. Internist (Berl) 49: 1159-1160, 2008 (In German).

14. Anastasilakis AD, Toulis KA, Polyzos SA and Terpos E: RANKL inhibition for the management of patients with benign metabolic bone disorders. Expert Opin Investig Drugs 18: 1085-1102, 2009.

15. Eghbali-Fatourechi G, Khosla S, Sanyal A, Boyle WJ, Lacey DL and Riggs BL: Role of Rank Ligand in mediating increased bone resorption in early post-menopausal women. J Clin Invest 111: 1221-1230, 2003.

16. von Knoch F, Jaquiery C, Kowalsky M, et al: Effects of bisphosphonates on proliferation and osteoblast differentiation of human bone marrow stromal cells. Biomaterials 26: 6941-6949, 2005.

17. Giner M, Rios MA, Montoya MA, et al: RANKL/OPG in primary cultures of osteoblasts from post-menopausal women. Differences between osteoporotic hip fractures and osteoarthritis. J Steroid Biochem Mol Biol 113: 46-51, 2009.

18. Wada N, Maeda H, Tanabe K, et al: Periodontal ligament cells secrete the factor that inhibits osteoclastic differentiation and function: the factor is osteoprotegerin/osteoclastogenesis inhibitory factor. J Periodontal Res 36: 56-63, 2001.

19. Owen TA, Aronow M, Shalhoub V, et al: Progressive development of the rat osteoblast phenotype in vitro: reciprocal relationships in expression of genes associated with osteoblast proliferation and differentiation during formation of the bone extracellular matrix. J Cell Physiol 143: 420-430, 1990.

20. Schwartz AV, Sellmeyer DE, Vittinghoff E, et al: Thiazolidinedione use and bone loss in older diabetic adults. J Clin Endocrinol Metab 91: 3349-3354, 2006.

21. Lin TH, Yang RS, Tang CH, Lin CP and Fu WM: PPARgamma inhibits osteogenesis via the down-regulation of the expression of COX-2 and iNOS in rats. Bone 41: 562-574, 2007.

22. Robinson JA, Harris SA, Riggs BL and Spelsberg TC: Estrogen regulation of human osteoblastic cell proliferation and differentiation. Endocrinology 138: 2919-2927, 1997. 